\title{
CORRIGENDUM
}

\section{Mutant mouse $p 53$ transgene elevates the chemical induction of tumors that respond to gene silencing with siRNA}

\section{H Tanooka, K Tatsumi, H Tsuji, Y Noda, T Katsube, H Ishii, A Ootsuyama, F Takeshita and $\mathbf{T}$ Ochiya}

Correction to: Cancer Gene Therapy advance online publication 26 June 2009; doi:10.1038/cgt.2009.43
In this article, Figure 3 was missing the labels for the $x$ axis and should have appeared as shown below.

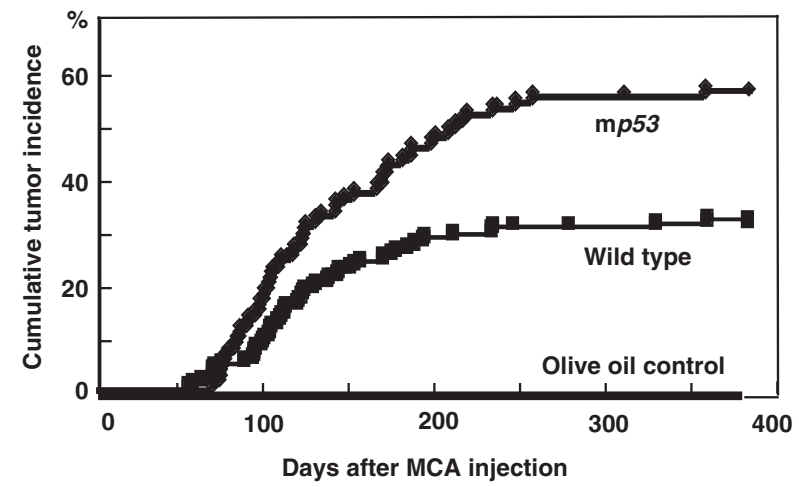

